\title{
Metabolism of aromatics by Trichosporon oleaginosus while remaining oleaginous
}

\author{
Allison Yaguchi, Alana Robinson, Erin Mihealsick and Mark Blenner ${ }^{*}$ (i)
}

\begin{abstract}
Background: The oleaginous yeast, Trichosporon oleaginosus, has been extensively studied for its ability to metabolize non-conventional feedstocks. These include phenol-containing waste streams, such as distillery wastewater, or streams consisting of non-conventional sugars, such as hydrolyzed biomass and various bagasse. An initial BLAST search suggests this yeast has putative aromatic metabolizing genes. Given the desirability to valorize underutilized feedstocks such as lignin, we investigated the ability of T. oleaginosus to tolerate and metabolize lignin-derived aromatic compounds.
\end{abstract}

Results: Trichosporon oleaginosus can tolerate and metabolize model lignin monoaromatics and associated intermediates within funneling pathways. Growth rates and biomass yield were similar to glucose when grown in 4-hydroxybenzoic acid (pHBA) and resorcinol, but had an increased lag phase when grown in phenol. Oleaginous behavior was observed using resorcinol as a sole carbon source. Fed-batch feeding resulted in lipid accumulation of $69.5 \%$ on a dry weight basis.

Conclusions: Though the exact pathway of aromatic metabolism remains to be determined for T. oleaginosus, the results presented in this work motivate use of this organism for lignin valorization and phenolic wastewater bioremediation. Trichosporon oleaginosus is the first yeast shown to be oleaginous while growing on aromatic substrates, and shows great promise as a model industrial microbe for biochemical and biofuel production from depolymerized lignin.

Keywords: Trichosporon oleaginosus, Aromatics, Phenol, Resorcinol, p-Hydroxybenzoic acid, Lignin, Yeast, Aromatic metabolism

\section{Background}

Valorization of lignocellulosic biomass wastes is critical for the economic viability of the biomass economy [1] Furthermore, valorization of wastewater and food and agricultural wastes may enhance sustainability and provide additional economic benefits [1, 2]. Waste streams are often heterogeneous in nature and contain additives and by-products, such as phenolics, that are toxic to human health. A by-product or waste that has gained considerable attention recently is lignin. It is the second-most abundant biopolymer on Earth and the only renewable, readily-available biopolymer comprised of

*Correspondence: blenner@clemson.edu

Department of Chemical and Biomolecular Engineering, Clemson

University, 206 S. Palmetto Blvd., Clemson, SC 29634, USA aromatics [1]. Lignin is a by-product of biomass used as a feedstock for biofuels and biochemical production, and is a prominent by-product of pulp and paper mills. Kraft lignin is typically burned for its heating value, and only $2 \%$ is recovered for nonfuel uses [3]. Rather than burning it, lignin could be utilized in biorefineries as a feedstock for microbial production of higher value products $[2,4]$. In addition, the large quantities of aromatics in industrial wastewater effluents makes aromatic compounds a prime target for waste valorization [5].

Bacterial metabolism and growth on various phenolic compounds is well-characterized. Many of these aromatics are representative lignin hydrolysate compounds or common products of lignin depolymerization [6]. Significant work has characterized phenolic metabolism in Rhodococcus opacus PD630 [7-9], Acinetobacter 
baylyi ADP1 [10, 11], and Pseudomonas putida [4, 1215]. There are fewer examples of yeast that have been characterized to grow on phenolics, such as Pichia holstii [16], Candida tropicalis [17], and Trichosporon cutaneum [18]. These yeasts have evolved to handle a wide variety of aromatic substrates, utilizing so-called funneling pathways to convert diverse molecular species into a small number of metabolites [19]. There are many pathways for aerobic aromatic metabolism, with the ortho- and meta-cleavage pathways being most common [19]. These pathways generate central metabolites, such as pyruvate and acetyl-CoA [20-23]. Understanding the biochemical pathways of aromatic metabolizing organisms enables downstream engineering for high value products, such as oleochemicals for pharmaceutical, fuel, and specialty chemical applications.

Oleaginous microorganisms are a rational starting point for microbial production of oleochemicals, such as lipids for biofuels and omega- 3 fatty acids. These microbes are characterized by their capacity to accumulate at least $20 \%$ of their mass as lipids. Significant attention has been given to several oleaginous yeast, including Yarrowia lipolytica [24-27], Lipomyces starkeyi [28], and Rhodosporidium toruloides [29]. Substantial work has been done to expand the genetic engineering tools available for these non-conventional oleaginous yeasts, enabling metabolic engineering of these species [30-36]. Despite being established industrial hosts with significant prior work, these yeast species are not suitable for utilizing certain low-cost feedstocks, such as aromaticrich lignin and phenolic wastewater streams. Given the 50 million tons of lignin currently produced per year [3], there is a great need for microorganisms that are able to tolerate and even metabolize aromatic feedstocks. Of the oleaginous microorganisms that tolerate aromatic toxicity, bacteria do not achieve a high enough biomass and are prone to phage infection, and white-rot fungi grow too slowly. Similarly, few oleaginous yeasts are known to metabolize aromatics. Furthermore, the oleaginous yeast shown to metabolize aromatics do not maintain high lipid accumulation under aromatic growth conditions.

This study addresses the narrow crossover between efficient aromatic metabolism, rapid growth kinetics, and high endogenous lipid accumulation by investigating Trichosporon oleaginosus, a non-model, non-conventional yeast previously known as Cryptococcus curvatus. A recent review summarizes the ability of $T$. oleaginosus to metabolize a number of non-conventional feedstocks and maintain oleagincity [37]. In this study, we found $T$. oleaginosus tolerates several aromatics and metabolizes them when used as a sole carbon source. Simultaneous growth on mixtures of sugars and aromatics appeared diauxic; however, both substrates were completely consumed. Finally, we demonstrate fed-batch growth on aromatics results in over $69 \%$ of biomass accumulated as lipids in a simple shake flask. Due to its rapid growth rate on aromatics, and its significant lipid accumulation, we suggest $T$. oleaginosus has great potential as a model system for aromatic metabolizing oleaginous yeast.

\section{Results \\ Trichosporon oleaginosus tolerates model lignin-derived aromatics}

A BLAST search of aromatic metabolism genes against the T. oleaginosus genome returns several putative orthocleavage enzymes and no hits from the meta-cleavage pathway, suggesting aromatic metabolism may use the ortho-cleavage route (Fig. 1) [4]. Given its potential for aromatic metabolism, and its known tolerance to several inhibitors, we reasoned that T. oleaginosus was likely to tolerate many aromatic compounds. Therefore, 15 model aromatic compounds were screened to determine the minimum inhibitory concentration (MIC), which is the minimum concentration completely inhibiting cell growth (Table 1). Notably, protocatechuate had the highest MIC at $15.5 \mathrm{~g} / \mathrm{L}$ for $T$. oleaginosus. The next highest MIC value was for hydroxyquinol at $7.5 \mathrm{~g} / \mathrm{L}$, followed by resorcinol at $5.5 \mathrm{~g} / \mathrm{L}$. Other compounds with MIC values over $1 \mathrm{~g} / \mathrm{L}$ included: 2,4-dihydroxybenzoic acid $(1.5 \mathrm{~g} / \mathrm{L})$, catechol $(3.0 \mathrm{~g} / \mathrm{L}), p$-coumarate $(1.4 \mathrm{~g} / \mathrm{L}), p$-hydroxybenzoic acid $(4.0 \mathrm{~g} / \mathrm{L})$, and phenol $(1.2 \mathrm{~g} / \mathrm{L})$.

\section{Trichosporon oleaginosus metabolizes model lignin-derived aromatics}

The tolerance to a number of different compounds suggests $T$. oleaginosus may be a good candidate for aromatic metabolism. To determine if this yeast has a natural metabolism of aromatic compounds, we chose three aromatics for further analysis-phenol, resorcinol, and 4-hydroxybenozic acid (pHBA). Resorcinol was picked over 2,4-dihydroxybenzoic acid because it had a higher MIC. Phenol was picked over benzoic acid because of the broad interest in phenol-containing waste stream in industry and similar MIC. pHBA was picked over all other compounds upstream of protocatechuate because it had the highest MIC. Each aromatic serves as a representative compound for a branch of the funneling pathways shown in Fig. 1. As a stringent test of metabolism, we picked compounds upstream in the pathway, but with tolerance high enough to allow for significant lipid accumulation. Trichosporon oleaginosus cells were grown in a minimal high nitrogen (TOHN) and low nitrogen (TOLN) media with $1 \mathrm{~g} / \mathrm{L}$ added carbon source (phenol, resorcinol, pHBA, or glucose). Growth curves shown in Fig. 2 represent growth in TOHN and are compared to a no-carbon-added negative control, which accounts for 


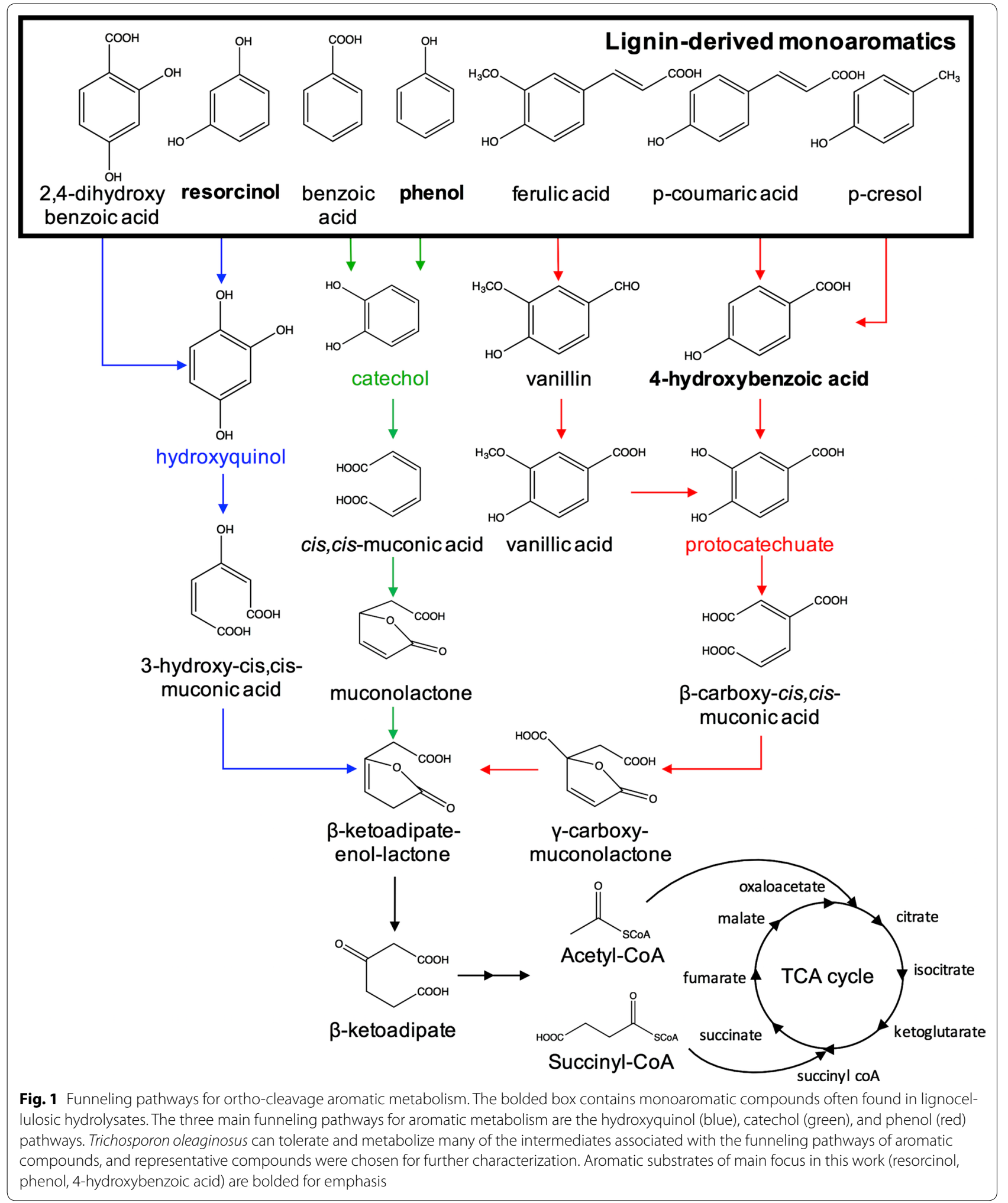

growth attributed to the small amount of yeast extract in the media. Media containing added carbon, whether glucose or aromatics, shows growth greater than the negative control, demonstrating that these substrate are metabolized for growth. All cells grown in media with an added carbon source reach similar biomass titers, 
Table 1 Minimum inhibitory concentrations (MICs) for compounds commonly found in lignin hydrolysates and funneling pathways for aromatic metabolism

\begin{tabular}{lc}
\hline Compound & MIC (g/L) \\
\hline 2,4-dihydroxybenzoic acid & 1.5 \\
Benzoic acid & 1.4 \\
Catechol & 3.0 \\
Ferulic acid & 0.6 \\
Guaiacol & 1.5 \\
Hydroxyquinol & 7.5 \\
p-Coumaric acid & 1.4 \\
p-Cresol & 0.8 \\
pHBA & 4.0 \\
Phenol & 1.2 \\
Protocatechuate & 15.5 \\
Resorcinol & 5.5 \\
Syringic acid & 2.0 \\
Vanillic acid & 1.6 \\
Vanillin & 0.2 \\
\hline
\end{tabular}

indicating that aromatic compounds do not deleteriously affect total biomass accumulation. Cells inoculated into resorcinol and pHBA-containing media grow similarly to each other and somewhat slower to cells inoculated into glucose, with specific growth rates for glucose, resorcinol, and pHBA of $0.157 \pm 0.016,0.0965 \pm 0.012$, and $0.092 \pm 0.001 \mathrm{~h}^{-1}$, respectively. Phenol induces a slower specific growth rate of $0.058 \pm 0.002 \mathrm{~h}^{-1}$ and has a longer lag phase, as cells did not enter exponential phase until $12 \mathrm{~h}$ after inoculation. The negative control has a growth rate of $0.101 \pm 0.010 \mathrm{~h}^{-1}$. Substrate utilization data, as measured by HPLC-UV-vis, indicate that all the compounds were fully consumed by $9 \mathrm{~h}$ for glucose, $12 \mathrm{~h}$ for resorcinol and $\mathrm{pHBA}$, and $30 \mathrm{~h}$ for phenol. In the high nitrogen media, lipid accumulation was slightly lower in phenol $(5.26 \pm 0.09 \% \mathrm{w} / \mathrm{w})$ as compared to resorcinol $(7.21 \pm 0.21 \% \mathrm{w} / \mathrm{w}), \mathrm{pHBA}(7.55 \pm 0.24 \% \mathrm{w} / \mathrm{w})$, and glucose $(6.72 \pm 0.29 \% \mathrm{w} / \mathrm{w})$ (Table 2). In low nitrogen media, lipid accumulation was slightly lower; however, given the toxicity limit for aromatic substrates, we were unable to create nitrogen limited condition needed for lipid accumulation using high concentrations of carbon in growth experiments. Furthermore, a small amount of yeast extract was needed for T. oleaginosus growth, limiting the achievable carbon to nitrogen $(\mathrm{C}: \mathrm{N})$ ratio to $12: 1$, assuming $11.1 \%$ nitrogen in the BD technical bacto yeast extract (reported in the BD bionutrients technical manual).

GC-FID was used to determine the fatty acid composition of cellular lipids (Table 3). This study agrees with previous reports that this yeast accumulates high amounts of linoleic acid and $\alpha$-linolenic acid when grown in glucose [38, 39]. However, cells grown with resorcinol, pHBA, and phenol show similar amounts of linoleic acid, an increase in oleic acid, and decrease in $\alpha$-linolenic acid (Table 3). When cells are grown in low nitrogen glucosecontaining media, lipid accumulation profiles show an increase in palmitic, palmitoleic, stearic, and oleic acid and a decrease in linoleic and $\alpha$-linoleic acid. In low nitrogen aromatic containing media, the lipid profiles are change in a substrate-dependent manner. For pHBA, low nitrogen resulted in increased palmitic acid, with small decreases to palmitoleic, stearic, linoleic acid, and alpha linolenic acid. For resorcinol, low nitrogen decreased palmitoleic, and stearic acid, resulting in higher oleic acid. Phenol was relatively unaffected by low nitrogen conditions.

Amongst the three aromatic compounds used in the metabolism studies, resorcinol could be used at a concentration of $3 \mathrm{~g} / \mathrm{L}$, the highest concentration with no change in the growth or health of the cells (data not shown). Therefore, we used this substrate in subsequent experiments to improve lipid accumulation from aromatics and to test different feeding strategies to effectively increase the $\mathrm{C}: \mathrm{N}$ ratio.

\section{Co-utilization of carbon sources results in diauxic growth}

Consolidated bioprocessing involving simultaneous biomass degradation and substrate utilization would contain sugars, such as glucose and xylose, and lignin-derived components; therefore, we measured growth in mixed carbon sources. Trichosporon oleaginosus demonstrates diauxic growth when grown in low nitrogen media comprised of $1.5 \mathrm{~g} / \mathrm{L}$ each of sugar (either glucose or xylose) and resorcinol (Fig. 3). Substrate utilization data show preferential metabolism of the sugars by hour 12 , followed by resorcinol; however, the slow consumption of resorcinol during the first $12 \mathrm{~h}$ suggests some degree of simultaneous utilization. The consumption rate of resorcinol increases significantly once the sugars are fully consumed. The resulting growth after glucose or xylose is fully consumed has a long lag phase until at least hour 30 , when cell growth continues. This observation is in contrast to $T$. oleaginosus growth in media containing both xylose and glucose, where glucose substrate was preferentially consumed, but the growth rates were similar between both carbon sources (Additional file 1: Figure S1). Measurements of cell density and lipid accumulation show no significant difference in percent lipid accumulation between xylose + resorcinol media, xylose media, and resorcinol media; however, lipid accumulation percentage in glucose was lower than resorcinol and both were lower than mixed glucose + resorcinol media (Table 4). However, it should be noted that due to the 

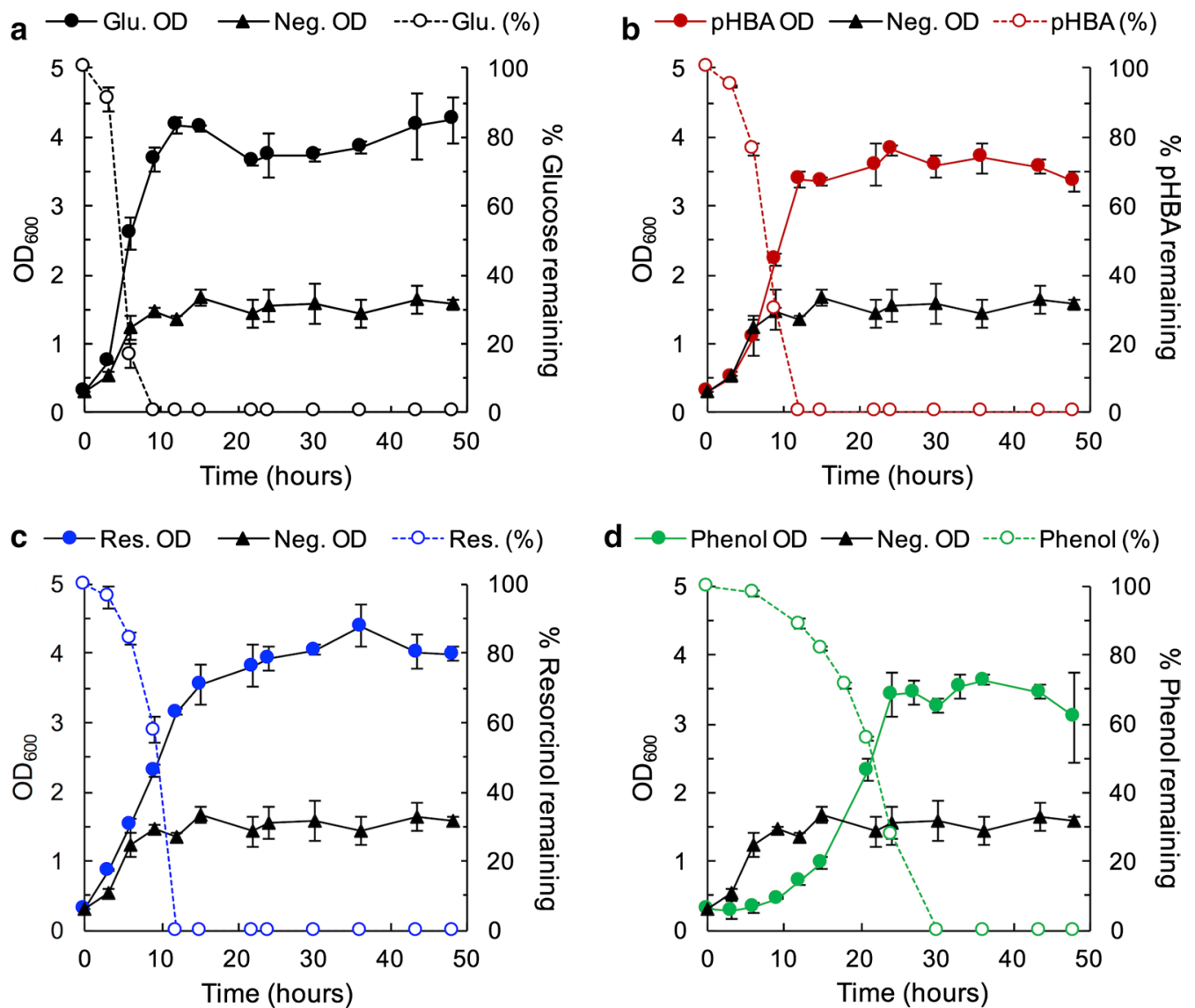

Fig. 2 Trichosporon oleaginosus can metabolize aromatic substrates. Growth (closed circles or triangle, solid lines) and substrate utilization (open circles, dashed lines) data for $1 \mathrm{~g} / \mathrm{L}$ a glucose, $\mathbf{b}$ pHBA, c resorcinol, and $\mathbf{d}$ phenol in TOHN media, respectively. The left axis represents $\mathrm{OD}_{600}$ while the right axis represents percent substrate remaining in the media. Growth in $1 \mathrm{~g} / \mathrm{L}$ of carbon is compared to a negative control containing no additional carbon source (closed triangle, solid line). Each panel shows full consumption of the aromatic compound. Cells grown in resorcinol and pHBA have growth rates approaching those grown in glucose, whereas cells grown in phenol had a longer lag phase and a slower growth rate. Substrates were chosen as representative compounds for each funneling pathway shown in Fig. 1. The data in $\mathbf{a}-\mathbf{d}$ are the mean and error bars are standard deviation of biological replicates $(n=3)$. Lines are used only for visual aid

Table 2 Measurement of dry cell weight, lipid titer, and percentage lipid accumulation in high nitrogen (TOHN) and low nitrogen (TOLN) media containing $1 \mathrm{~g} / \mathrm{L}$ carbon

\begin{tabular}{llllc}
\hline Substrate & N conc. $(\mathbf{g} / \mathbf{L})$ & Dry cell weight $\mathbf{( g / L )}$ & Lipid titer $(\mathbf{g} / \mathbf{L})$ & Lipid accumulation (\%) \\
\hline Glucose & 4 & $0.71 \pm 0.00$ & $0.05 \pm 0.00$ & $6.72 \pm 0.29$ \\
Resorcinol & 4 & $0.70 \pm 0.06$ & $0.05 \pm 0.00$ & $7.21 \pm 0.21$ \\
pHBA & 4 & $0.64 \pm 0.05$ & $0.05 \pm 0.00$ & $7.55 \pm 0.24$ \\
Phenol & 4 & $0.80 \pm 0.01$ & $0.04 \pm 0.00$ & $5.26 \pm 0.09$ \\
Negative & 4 & $0.22 \pm 0.03$ & $0.03 \pm 0.00$ & $12.22 \pm 1.20$ \\
Glucose & 0.012 & $0.96 \pm 0.02$ & $0.05 \pm 0.01$ & $5.44 \pm 1.04$ \\
Resorcinol & 0.012 & $0.66 \pm 0.01$ & $0.03 \pm 0.01$ & $4.67 \pm 1.24$ \\
pHBA & 0.012 & $0.69 \pm 0.02$ & $0.03 \pm 0.00$ & $4.72 \pm 0.23$ \\
Phenol & 0.012 & $0.80 \pm 0.01$ & $0.05 \pm 0.00$ & $6.13 \pm 0.25$ \\
Negative & 0.012 & $0.28 \pm 0.00$ & $0.02 \pm 0.00$ & $6.11 \pm 0.69$ \\
\hline
\end{tabular}

Errors are reported as standard deviation of biological triplicates 
use of a small amount of yeast extract, the C:N value of $36: 1$ is still somewhat low, discouraging significant lipid accumulation. Lipid profiles show consistent distribution of fatty acids across various carbon sources (Additional file 1: Table S1).
T. oleaginosus remains oleaginous while metabolizing high concentration of aromatics

As noted earlier, $3 \mathrm{~g} / \mathrm{L}$ was the highest concentration of resorcinol tested that did not result in a lower growth rate. While non-inhibited growth on this concentration of resorcinol is already high compared to other yeast

Table 3 Fatty acid composition profile (\%) for cells grown in high nitrogen (TOHN) and low nitrogen (TOLN) media containing $1 \mathrm{~g} / \mathrm{L}$ carbon

\begin{tabular}{llrlllll}
\hline Substrate & N conc. $(\mathbf{g} / \mathbf{L})$ & \multicolumn{1}{c}{ C16:0 } & C16:1 & C18:0 & C18:1 & C18:2 & C18:3 \\
\hline Glucose & 4 & $8.9 \pm 1.2$ & $14.2 \pm 0.4$ & $6.6 \pm 0.4$ & $19.7 \pm 0.4$ & $41.4 \pm 2.1$ & $9.2 \pm 0.1$ \\
Resorcinol & 4 & $9.1 \pm 0.5$ & $14.5 \pm 0.6$ & $6.5 \pm 0.2$ & $31.6 \pm 1.1$ & $38.3 \pm 2.1$ & $0.0 \pm 0.0$ \\
pHBA & 4 & $10.1 \pm 0.7$ & $14.2 \pm 0.4$ & $7.6 \pm 0.7$ & $30.8 \pm 1.3$ & $36.0 \pm 0.6$ & $1.4 \pm 1.9$ \\
Phenol & 4 & $8.6 \pm 0.5$ & $11.1 \pm 0.3$ & $6.1 \pm 0.6$ & $37.9 \pm 3.5$ & $36.3 \pm 2.2$ & $0.0 \pm 0.0$ \\
Glucose & 0.012 & $12.5 \pm 0.4$ & $17.4 \pm 0.5$ & $8.0 \pm 0.3$ & $26.2 \pm 0.3$ & $29.3 \pm 0.4$ & $6.7 \pm 0.1$ \\
Resorcinol & 0.012 & $8.5 \pm 4.4$ & $9.9 \pm 4.9$ & $0.0 \pm 0.0$ & $43.1 \pm 6.4$ & $38.5 \pm 2.8$ & $0.0 \pm 0.0$ \\
pHBA & 0.012 & $18.0 \pm 0.5$ & $13.4 \pm 0.4$ & $4.0 \pm 2.9$ & $31.9 \pm 1.7$ & $32.6 \pm 1.4$ & $0.0 \pm 0.0$ \\
Phenol & 0.012 & $7.5 \pm 0.5$ & $13.1 \pm 0.1$ & $6.9 \pm 0.2$ & $39.5 \pm 1.2$ & $32.9 \pm 1.2$ & $0.0 \pm 0.0$ \\
\hline
\end{tabular}

Errors are reported as standard deviation of biological triplicates
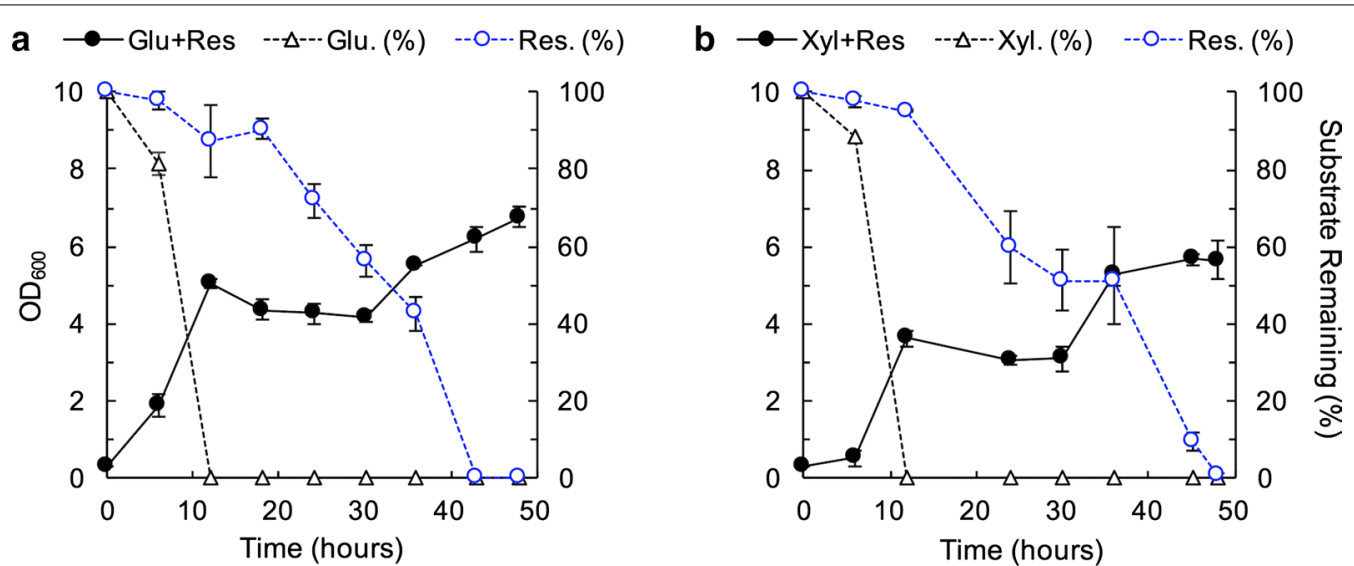

Fig. 3 Diauxic growth of T. oleaginosus cells when cultured in dual-carbon media. a TOLN media containing $1.5 \mathrm{~g} / \mathrm{L} \mathrm{glucose}+1.5 \mathrm{~g} / \mathrm{L}$ resorcinol and b TOLN media containing $1.5 \mathrm{~g} / \mathrm{L}$ Xylose $+1.5 \mathrm{~g} / \mathrm{L}$ resorcinol. Growth (closed circles, solid lines) and substrate utilization (open markers, dashed lines) for sugars (black) and resorcinol (blue). The left axis represents $\mathrm{OD}_{600}$ while the right axis represents percent substrate remaining in the media. Sugars are preferentially consumed, although resorcinol is partially consumed by hour 12 in both mixed carbon media. The cell density remains unchanged for $18 \mathrm{~h}$ after exhaustion, resulting in diauxic growth. The data are the mean and error bars are standard deviation of biological replicates $(n=3)$. Lines are used only for visual aid

Table 4 Measurement of dry cell weight, lipid titer, and percentage lipid accumulation for cells grown in dual-carbon media and comparison to single carbon media

\begin{tabular}{lllllr}
\hline Substrate & C conc. $(\mathbf{g} / \mathbf{L})$ & N conc. $(\mathbf{g} / \mathbf{L})$ & Dry cell weight $\mathbf{( g / L )}$ & Lipid titer $(\mathbf{g} / \mathbf{L})$ & Lipid accumulation $(\%)$ \\
\hline Xylose & 3.0 & 0.0012 & $1.6 \pm 0.0$ & $0.23 \pm 0.0$ & $14.5 \pm 0.7$ \\
Glucose & 3.0 & 0.0012 & $1.2 \pm 0.0$ & $0.10 \pm 0.0$ & $8.2 \pm 0.2$ \\
Resorcinol & 3.0 & 0.0012 & $1.0 \pm 0.1$ & $0.11 \pm 0.0$ & $11.3 \pm 1.0$ \\
Xyl + Res & $1.5 / 1.5$ & 0.0012 & $1.2 \pm 0.4$ & $0.14 \pm 0.0$ & $12.6 \pm 3.1$ \\
Glu + Res & $1.5 / 1.5$ & 0.0012 & $0.7 \pm 0.0$ & $0.10 \pm 0.0$ & $13.9 \pm 1.7$
\end{tabular}

Errors are reported as standard deviation of biological triplicates 
[37], we sought to determine if more substrate could be utilized using alternative feeding strategies. The first attempt feed more resorcinol was through a two-stage feeding strategy where $T$. oleaginosus cells were grown for $30 \mathrm{~h}$ in TOLN containing $3 \mathrm{~g} / \mathrm{L}$ resorcinol to accumulate biomass. The time of $30 \mathrm{~h}$ was chosen because the cells are in late exponential phase at this point (Fig. 4). Cells were harvested and resuspended in fresh TOLN $(\mathrm{C}: \mathrm{N}=36: 1)$ or with fresh defined low nitrogen (DLN) media (C:N = 361:1), both containing $3 \mathrm{~g} / \mathrm{L}$ resorcinol and grown for another $48 \mathrm{~h}$. DLN media use was possible once cell biomass was obtained in the first stage, and the yeast extract could be omitted from the TOLN media. The DLN C:N ratio was altered to match that of previously established $\mathrm{C}: \mathrm{N}$ ratios [40] by eliminating yeast extract and supplementing nitrogen in the form of ammonium sulfate. Two-stage feeding is required because DLN alone does not promote significant biomass accumulation $(0.12 \pm 0.0 \mathrm{~g} / \mathrm{L}$ cell density after $80 \mathrm{~h}$ ). The higher $\mathrm{C}: \mathrm{N}$ ratio was better for lipid accumulation (Table 5). Switching into a lipid accumulating media results in a $60 \%$ improvement in lipid accumulation from
$14.5 \pm 0.9$ to $35.9 \pm 1.2 \%$ (Table 5 ) while maintaining a similar lipid composition profile similar to that of previous experiments (Additional file 1: Table S2).

\section{T. oleaginosus accumulates greater than $69 \%$ of its biomass as lipids in a fed-batch shake flask using resorcinol as a sole carbon source}

Cells for the fed-batch experiment were initially inoculated to an OD of 0.3 in TOLN containing $3 \mathrm{~g} / \mathrm{L}$ of resorcinol and were grown for $36 \mathrm{~h}$. After this time, $2 \mathrm{~g} / \mathrm{L}$ of resorcinol were fed every $24 \mathrm{~h}$ while keeping the culture volume constant (Fig. 5). In this manner, nutrients such as nitrogen were depleted over time, and only carbon was replenished with every feeding. A total of $11 \mathrm{~g} / \mathrm{L}$ of resorcinol was delivered over $160 \mathrm{~h}$, as compared to $3 \mathrm{~g} / \mathrm{L}$ over $48 \mathrm{~h}$ in batch experiments, resulting in a 73\% improvement in total carbon fed. Fed-batch feeding results in $87.4 \%$ improvement in total lipid titer from $0.11 \pm 0.0 \mathrm{~g} / \mathrm{L}$ (Table 4) to $1.64 \pm 0.2 \mathrm{~g} / \mathrm{L}$ (Table 5). Lipid accumulation increased from $11.3 \pm 0.0 \%$ (Table 4 ) to $69.5 \pm 4.0 \%$ (Table 5), resulting in an $87.4 \%$ improvement. When compared to the two-stage feeding described earlier, lipid
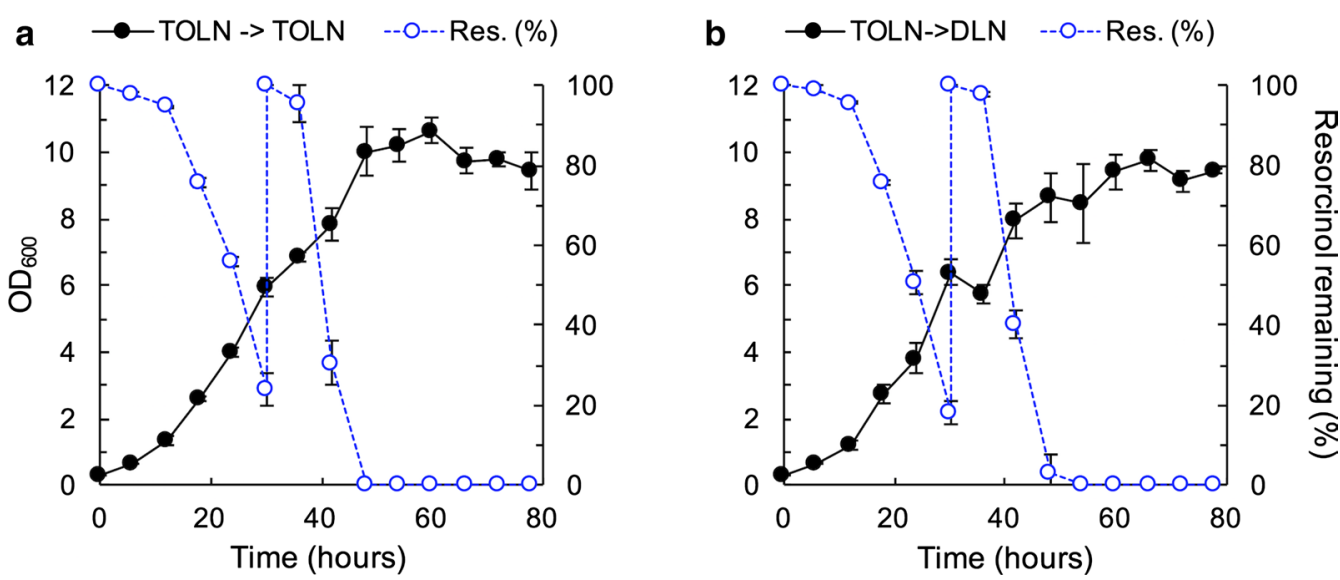

Fig. 4 Two-stage feeding cultures demonstrate complete consumption of resorcinol and no metabolic limitations. Growth (closed circles, solid lines) is on the left axis and substrate utilization (open circles, dashed lines) is on the right axis. a Cells are grown for $30 \mathrm{~h}$ in TOLN media containing $3 \mathrm{~g} / \mathrm{L}$ resorcinol (C:N ratio $=36: 1$ ). After $30 \mathrm{~h}$, cells are switched into fresh TOLN media containing $3 \mathrm{~g} / \mathrm{L}$ resorcinol (C:N $=36: 1)$ and grown for an additional $48 \mathrm{~h}$. b Cells are grown for $30 \mathrm{~h}$ in TOLN media containing $3 \mathrm{~g} / \mathrm{L}$ resorcinol (C:N ratio $=36: 1)$. After $30 \mathrm{~h}$, cells are switched into fresh defined low nitrogen (DLN) media containing $3 \mathrm{~g} / \mathrm{L}$ resorcinol ( $\mathrm{C}: \mathrm{N}=361: 1)$ and grown for an additional $48 \mathrm{~h}$. The data are the mean and error bars are standard deviation of biological replicates $(n=3)$. Lines are used only for visual aid

Table 5 Measurement of dry cell weight, lipid titer, and percentage lipid accumulation for two-stage and fed-batch cultures

\begin{tabular}{llllll}
\hline Sample & Final C conc. (g/L) & Final N conc. (g/L) & Dry cell weight (g/L) & Lipid titer (g/L) & Lipid accumulation (\%) \\
\hline TOLN $\rightarrow$ TOLN & 6.0 & 0.00120 & $1.81 \pm 0.0$ & $0.26 \pm 0.1$ & $14.5 \pm 0.9$ \\
TOLN $\rightarrow$ DLN & 6.0 & 0.00012 & $1.48 \pm 0.1$ & $0.53 \pm 0.0$ & $35.9 \pm 1.2$ \\
Fed batch & 11.0 & 0.00120 & $2.36 \pm 0.2$ & $1.64 \pm 0.2$ & $69.5 \pm 4.0$ \\
\hline
\end{tabular}

Errors are reported as standard deviation of biological triplicates 
titer improved by $39.1 \%$ and lipid accumulation improved by $38.8 \%$. The lipid profile was similar to those found in two-stage feeding experiments (Additional file 1: Table S2).

\section{Discussion}

Trichosporon oleaginosus has been studied for its ability to accumulate a significant amount of lipids from a variety of feedstocks. This is the first report showing that $T$. oleaginosus is able to metabolize model lignin monoaromatic compounds when used as a sole carbon source. It is likewise the first report of $T$. oleaginosus metabolizing aromatics in mixed sugar and aromatic substrates. While other yeast have been shown to tolerate and metabolize aromatic compounds [41], this is the first demonstration of yeast growing on aromatics and accumulating lipids greater than $20 \%$ on a dry weight basis. In fed-batch experiments, T. oleaginosus was able to accumulate over $69 \%$ of its dry cell weight as lipids using aromatic compound resorcinol as the sole carbon source, demonstrating its promise as a model organism for aromatic to oleochemical conversion.

To date, the highest reported lipid accumulation from T. oleaginosus is $73.4 \%$ on a dry weight basis using acetate as the sole carbon source [42]. This lipid accumulation compares favorably to the lipid accumulation of $69.5 \%$ on a dry weight basis from resorcinol demonstrated in this work. We were unable to find any report of lipid accumulation in a microbe grown on resorcinol as the sole carbon source. The literature has focused on bioremediation of xenobiotics and anthropomorphic aromatic substrates rather than lipid accumulation. Amongst oleaginous bacteria, Rhodococcus opacus strains DSM 1069 and PD630, accumulate up to $20 \%$ of dry weight as lipids when grown on pHBA and vanillic acid in optimized fed-batch reactors [8]. Phenol toxicity impacted the growth rate when reaching $0.3 \mathrm{~g} / \mathrm{L}$ [9]. A strain of $R$. opacus PD630 evolved for higher tolerance, increasing from $0.3 \mathrm{~g} / \mathrm{L}$ up to $1.5 \mathrm{~g} / \mathrm{L}$ achieving lipid accumulation of $11.7 \%$ on a dry weight basis [9]. The titer was not reported, but could not be higher than $1.5 \mathrm{~g} / \mathrm{L}$, the concentration of phenol used in the experiments, and theoretically must be much lower. By comparison, our highest lipid titer was $1.64 \pm 0.2 \mathrm{~g} / \mathrm{L}$ with a lipid accumulation of $69.3 \%$ and was achieved using a wild-type strain. Trichosporon oleaginosus is able to accumulate significantly higher titers of lipids when grown on higher concentrations of preferred substrates such as glucose $[38,39,43]$; however, the toxicity of aromatic compounds limits the concentration of aromatics dosed at a single time. The toxicity limitation of aromatic substrates limits the carbon to nitrogen $(\mathrm{C}: \mathrm{N})$ ratio when growing initial cell biomass, which benefits significantly from a small amount of yeast extract. In one study, $T$. oleaginosus was previously shown to achieve the highest percent accumulation and lipid titer at a C:N ratio of 99 [44], whereas another study used a C:N ratio of 360 [40]. These high C:N ratios are consistent with our observations of poor lipid accumulation using a C:N ratio of 36 , but drastically greater lipid accumulation using a ratio of 360:1 in fed-batch experiments, emphasizing the role of the C:N ratio on lipid accumulation in T. oleaginosus.

In nature, lignin can be enzymatically depolymerized to a wide variety of aromatics. Similarly, catalytic depolymerization also results in a heterogeneous mixture of aromatic compounds [41]. Funneling pathways overcome the inherent heterogeneity of lignin by converting key aromatic compounds to important intermediates for the TCA cycle [4, 20-23]. The beta-ketoadipate pathway is well-conserved amongst aromatic metabolizing bacteria and yeast. The most common pathways are intra-diol (ortho) ring cleavage and extra-diol (meta) ring cleavage pathways. Based on our demonstration of resorcinol, pHBA, and phenol metabolism, T. oleaginosus appears to have each of the three major funneling pathways. The enzymatic activity of aromatic metabolism was previously studied in Trichosporon cutaneum. Metabolite analysis demonstrated ortho ring cleavage reaction products and the absence of meta ring cleavage products [45, 46]. Given both are from the same genus, it is likely that T. oleaginosus uses the ortho ring cleavage pathway. A more detailed study is needed to definitively identify the pathways for aromatic metabolism.

Lignocellulosic hydrolysates contain sugars derived from the cellulose and hemicellulose content and aromatics from the lignin content; therefore, our demonstration that $T$. oleaginosus co-utilizes resorcinol and sugars (glucose or xylose) establishes the potential to utilize multiple components of lignocellulosic biomass. Given that $T$. oleaginosus can co-utilize glucose and xylose (Additional file 1: Figure S1), we expect that this yeast will co-utilize glucose, xylose, and aromatics. In addition, this finding suggests it may be unnecessary to remove phenolic content in recalcitrant feedstocks, as is typically required due aromatic toxicity and lack of metabolism [47]. Related organisms show similar co-utilization. In fact, wild type T. cutaneum was shown to simultaneously uptake glucose and phenol, with the rate of glucose utilization being much higher than that of phenol utilization [48], consistent with our findings. The presence of glucose decreased phenol utilization and catechol-1,2 dioxygenase (an enzyme belonging to the catechol funneling pathway) activity by 60 and $75 \%$, respectively.

We show $T$. oleaginosus is able to tolerate 15 different compounds to various degrees, with MICs as high as $15.5 \mathrm{~g} / \mathrm{L}$ for protocatechuate and as low as $0.2 \mathrm{~g} / \mathrm{L}$ for vanillin. Improving tolerance will be important for 


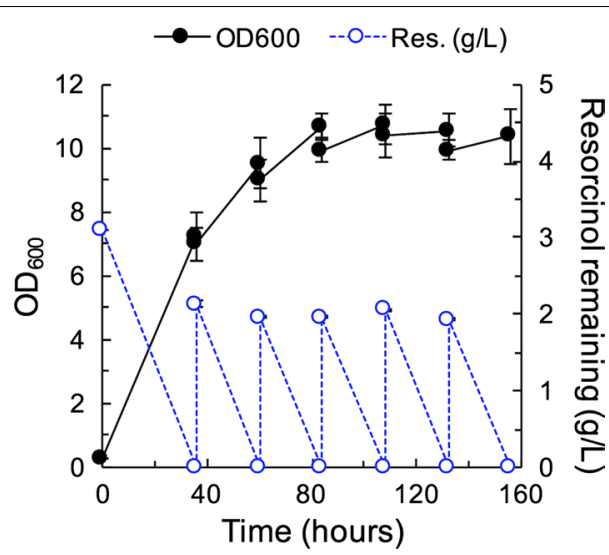

Fig. 5 Fed-batch feeding strategy results in significant resorcinol metabolism over a prolonged period. Growth (closed circles, solid lines) are on the left axis and substrate utilization (open circles, dashed lines) are on the right axis. Initial TOLN media contained $3 \mathrm{~g} / \mathrm{L}$ resorcinol. After $36 \mathrm{~h}$, cells were fed with $2 \mathrm{~g} / \mathrm{L}$ resorcinol in $24 \mathrm{~h}$ intervals while keeping culture volume constant. Cultures show full resorcinol consumption after each feeding; however, cell growth plateaus, potentially indicating high lipid accumulation in the late phase of culturing. The data are the mean and error bars are standard deviation of biological replicates $(n=5)$. Lines are used only for visual aid

further development of industrially relevant strains. Several mechanisms have been reported to avoid aromatic toxicity including dynamic lipid distribution, efficient transporters, and highly active aromatic conversion genes. The mechanism for aromatic tolerance in bacteria is mostly attributed to redistribution of the highly dynamic lipid composition and the activation of aromatic efflux transporters [49-53]. Pseudomonas putida strains isolated from toluene-polluted sites responded to aromatic-induced membrane stress by increasing the ratio of trans and cis fatty acid isomers, making the cell membrane more rigid. Pseudomonas putida DOT-T1E has been shown to tolerate and metabolize $17 \mathrm{~g} / \mathrm{L}$ pHBA, which the authors attribute to the cell membrane rigidity [54]. A more recent study showed the fatty acid composition of $R$. opacus strains grown on phenol and benzene also exhibited increased trans-fatty acids and increased 10-methyl branched fatty acid content in the presence of aromatics [51]. While these specific membrane adaptations are unique to prokaryotes, eukaryotes can likewise alter membrane fluidity through alterations in composition and sterols [55]. Aside from altering membrane fluidity, strains of $P$. putida have been shown to utilize efflux pumps to remove toluene from the cell membrane $[50,53]$. However, efflux pumps would be counter to the desired aromatic metabolism. Recently, an evolved strain of $R$. opacus PD630 showed increased importer activity led to faster growth on phenol, and higher tolerance to phenol compared to the wild type strain [9]. Lastly, a recent study in Saccharomyces cerevisiae shows that enabling efficient conversion genes also improves tolerance by removing the toxic compounds and converting them to a more benign intermediate [56].

We hypothesize that $T$. oleaginosus uses a combination of these mechanisms. The fatty acid distribution changes in the presence of aromatic compounds as compared to glucose, with glucose resulting in $\mathrm{C} 18: 3$, but aromatic grown cells have a higher content of C18:1 and C18:2. The identical growth rates of cells using glucose, pHBA, or resorcinol suggest the potential for efficient metabolism of aromatics. Enhancing import or metabolism of aromatics could lead to improved tolerance. The recent demonstration of genetic engineering tools for $T$. oleaginosus [38] makes it possible to engineer increased tolerance through control of membrane fluidity and overexpression of rate limiting aromatic metabolism genes. Improving aromatic tolerance in this, and any microbe, is necessary to economically utilize higher concentrations of substrate for industrial applications, further motivating future studies understanding the mechanism for aromatic metabolism and tolerance and engineering improvements.

\section{Conclusions}

Trichosporon oleaginosus is the first yeast shown to metabolize aromatics and remain oleaginous, accumulating nearly $70 \%$ of its biomass as lipids when grown on resorcinol in fed-batch. This yeast shows promise for utilizing aromatic-containing feedstocks, such as lignin and wastewater effluent, for microbial production of oleochemicals or aromatic-derived compounds due to its natural ability to tolerate and metabolize relatively high concentrations of aromatics. A complete understanding coupled to additional metabolic engineering tools will enable pathway engineering for improving tolerance to and conversion of aromatics for industrial applications. Nevertheless, this yeast is well-positioned to become a model system for aromatics metabolism to lipids and oleochemicals.

\section{Methods and materials Reagents}

A list of all chemical reagents used and the source of these chemicals is listed in Additional file 1: Table S3. All enzyme reagents were purchased from New England Biolabs (Ipswich, MA) unless otherwise stated. Trichosporon oleaginosus was obtained from the American Type Culture Center $\left(\mathrm{ATCC}^{\circledR} 20509^{\mathrm{TM}}\right.$ ).

\section{Tolerance studies}

Tolerance studies were performed in 48-well plates (Nunclon $^{\circledR} 48$-well plate) in a Biotek ${ }^{\circledR}$ Synergy $^{\text {TM }} \mathrm{Mx}$ 
multimode microplate reader. $2 \mathrm{~mL}$ YPD pre-cultures were grown overnight and used to inoculate $250 \mu \mathrm{L}$ YPD (10 g/L yeast extract, $20 \mathrm{~g} / \mathrm{L}$ peptone, $20 \mathrm{~g} / \mathrm{L}$ glucose) containing various aromatic compounds described in Table 1 to an OD $=0.3$. Cells were grown over $48 \mathrm{~h}$ in a 48 well plate with the lid on, fast shake speed, and at $28{ }^{\circ} \mathrm{C}$. The plate reader scanned every hour at $600 \mathrm{~nm}$. Studies were performed at least in triplicate. Hydroxyquinol and catechol resulted in media color changes that prevented use of the spectrophotometric measurement, so these samples were plated to assess CFUs.

\section{Aromatic growth studies}

Single and dual carbon source cultures were cultured in the same fashion. Trichosporon oleaginosus (ATCC ${ }^{\circledR}$ $20509^{\mathrm{TM}}$ ) cells were grown in $2 \mathrm{~mL}$ YPD pre-cultures overnight. Cells were washed three times with new media, and inoculated to an initial $\mathrm{OD}_{600}$ of 0.3 in $50 \mathrm{~mL}$ baffled Erlenmeyer Corning ${ }^{\circledR}$ flasks containing $15 \mathrm{~mL}$ of either high nitrogen (TOHN) or low nitrogen (TOLN) media (modified from [40]) with appropriate carbon source and concentration. Details on media composition are included in Additional file 1: Table S4. Cell washing entailed centrifuging cells at $1100 \times g$ for $4 \mathrm{~min}$ at $4{ }^{\circ} \mathrm{C}$, decanting supernatant, and re-suspending in destination media. Carbon sources included glucose, xylose, phenol, resorcinol, and 4-hydroxybenzoic acid (pHBA). Optical density (OD) readings were measured on a Thermo Scientific NanoDrop ${ }^{\mathrm{TM}} 2000$ at $600 \mathrm{~nm}$ and corrected by a factor of 17.725. All experiments were performed in triplicate.

Two-stage feeding and fed-batch cultures were started in the same manner. After biomass accumulation in the two-stage feeding experiments, the whole cell culture was transferred to a $50 \mathrm{~mL}$ centrifuge tube, spun down at $4000 \mathrm{rpm}$ for $3 \mathrm{~min}$ at $4{ }^{\circ} \mathrm{C}$, and re-suspended in $15 \mathrm{~mL}$ fresh TOLN or DLN (Additional file 1: Table S5) media. The entire $15 \mathrm{~mL}$ was transferred back to the $50 \mathrm{~mL}$ baffled flask and cultured for the $48 \mathrm{~h}$ lipid accumulation phase. For fed-batch experiments, $1.5 \mathrm{~mL}$ of cell culture was removed after the initial biomass accumulating phase. Stock resorcinol $\left(20 \mathrm{~g} / \mathrm{L}\right.$ in $\left.\mathrm{ddH}_{2} \mathrm{O}\right)$ was added to feed $2 \mathrm{~g} / \mathrm{L}$ at a time. This removal of biomass and addition of stock resorcinol was repeated every $24 \mathrm{~h}$ until the end of the experiment. All experiments were performed in triplicate.

\section{Dry cell weight and lipid analysis}

Cells were harvested for dry cell weight by washing $10 \mathrm{~mL}$ of cell culture with $20 \mathrm{~mL}$ of $\mathrm{dd}_{2} \mathrm{O}$ three times and drying overnight at $40{ }^{\circ} \mathrm{C}$ under vacuum in aluminum pans. Dry cell weights were measured using an analytical balance. To identify and quantify lipids in cell biomass, extracted cellular lipids were transesterified to FAMEs as described previously with minor modifications. Briefly, $1 \mathrm{~mL}$ cell culture was harvested and spun down at $13,000 \mathrm{rpm}$ for $3 \mathrm{~min}$ at $25^{\circ} \mathrm{C}$. $100 \mu \mathrm{L}$ glyceryl triheptadecanoate at a concentration of $2 \mathrm{mg} / \mathrm{mL}$ methanol was added to the cell pellet as an internal standard. Lipids were transesterified to FAMEs with $500 \mu \mathrm{L}$ of $0.5 \mathrm{~N}$ sodium methoxide followed by $30 \mathrm{~min}$ of vortexing at $2000 \mathrm{rpm}$. The solution was neutralized with $40 \mu \mathrm{L}$ sulfuric acid. FAMEs were extracted by adding $850 \mu \mathrm{L}$ hexane followed by $20 \mathrm{~min}$ of vortexing at $2000 \mathrm{rpm}$. The mixture was centrifuged for $1 \mathrm{~min}$ at $8000 \mathrm{rpm}$, and 800 $\mu \mathrm{L}$ of the organic layer was collected for GC-FID analysis (Agilent 7890B) and quantification [32].

\section{Substrate utilization}

Aromatic substrate utilization was analyzed using a Waters 600E multisolvent delivery (Waters Corporation) high performance liquid chromatography (HPLC) system with a BioRad Fast Acid Analysis HPLC column with 10\% $\mathrm{v} / \mathrm{v}$ acetonitrile and $0.01 \mathrm{~N} \mathrm{H}_{2} \mathrm{SO}_{4}$ in a 1:1 mixture as the eluent, a flow rate $0.6 \mathrm{~mL} / \mathrm{min}$, temperature of $65^{\circ} \mathrm{C}$, and with a Waters 996 PDA detector. Phenol was detected at $270 \mathrm{~nm}$, resorcinol at $274 \mathrm{~nm}$, and pHBA at $254 \mathrm{~nm}$. Glucose and xylose were measured using the same column at $85{ }^{\circ} \mathrm{C}, 5 \mathrm{mM} \mathrm{H}_{2} \mathrm{SO}_{4}$ eluent, and a Waters 2414 refractometer. Concentrations were calculated from standard curves created for each carbon source in the appropriate medium.

\section{Additional file}

Additional file 1. Additional data related to dual-carbon source experiments and methods. Figure S1. Growth curves and substrate consumption data for glucose, xylose, resorcinol, and glucose/xylose. Table S1. Dual-carbon source fatty acid distribution. Table S2. Two-stage and fedbatch fatty acid composition. Table S3. List of chemical suppliers. Tables S4, S5. Media composition.

\section{Abbreviations}

TOHN: Trichosporon oleaginosus high nitrogen; TOLN: Trichosporon oleaginosus low nitrogen; DLN: defined low nitrogen; pHBA: 4-hydroxybenzoic acid; HPLC: high performance liquid chromatography; GC-FID: gas chromatography-flame ionization detection.

\section{Authors' contributions}

$A Y$ and $M A B$ contributed to writing and editing the manuscript and designed the experimental approach. AY and AMR performed data collection on TOHN and TOLN characterization. AY performed data collection on co-utilization, two-stage, and fed-batch. EM collected data for the toxicity experiments. All authors read and approved the final manuscript.

\section{Acknowledgements}

We would like to acknowledge Dr. David Bruce for access to the GC, Dr. Mark Thies for access to the HPLC, Dr. Scott Husson for access to the HPLC column, and Dr. Nishanth Tharayil for access to some aromatic compounds. We would also like to thank Murtaza Shabbir Hussain and Dyllan Rives for helpful comments. 


\section{Competing interests}

The authors declare that they have no competing interests.

\section{Availability of data and materials}

The datasets supporting the conclusions of this article are included within the article.

\section{Consent for publication}

Not applicable.

\section{Ethics approval and consent to participate}

Not applicable.

\section{Funding}

This study was funded in part by a USDA Sun Grant (2014-38502-22598). This work was also supported by Creative Inquiry funds from Clemson University.

\section{Publisher's Note}

Springer Nature remains neutral with regard to jurisdictional claims in published maps and institutional affiliations.

Received: 21 August 2017 Accepted: 11 November 2017

Published online: 17 November 2017

\section{References}

1. Tuck CO, Perez E, Horvath IT, Sheldon RA, Poliakoff M. Valorization of biomass: deriving more value from waste. Science. 2012;337:695-9.

2. Ragauskas AJ, Beckham GT, Biddy MJ, Chandra R, Chen F, Davis MF, Davison $\mathrm{BH}$, Dixon RA, Gilna P, Keller M, et al. Lignin valorization: improving lignin processing in the biorefinery. Science. 2014;344:1246843.

3. Gosselink RJA, de Jong E, Guran B, Abacherli A. Co-ordination network for lignin - standardisation, production and applications adapted to market requirements (EUROLIGNIN). Ind Crops Prod. 2004;20:121-9.

4. Linger JG, Vardon DR, Guarnieri MT, Karp EM, Hunsinger GB, Franden MA, Johnson CW, Chupka G, Strathmann TJ, Pienkos PT, Beckham GT. Lignin valorization through integrated biological funneling and chemical catalysis. Proc Natl Acad Sci USA. 2014;111:12013-8.

5. Cordova Villegas L, Mashhadi N, Chen M, Mukjerjee D, Taylor K, Biswas N. A short review of techniques for phenol removal from wastewater. Curr Pollut Rep. 2016:2:157-67.

6. Wang H, Tucker M, Ji Y. Recent development in chemical depolymerization of lignin: a review. J Appl Chem. 2013;2013:1-9.

7. Hollinshead WD, Henson WR, Abernathy M, Moon TS, Tang YJJ. Rapid metabolic analysis of Rhodococcus opacus PD630 via parallel C-13-metabolite fingerprinting. Biotechnol Bioeng. 2016;113:91-100.

8. Kosa M, Ragauskas AJ. Bioconversion of lignin model compounds with oleaginous Rhodococci. Appl Microbiol Biotechnol. 2012;93:891-900.

9. Yoneda A, Henson WR, Goldner NK, Park KJ, Forsberg KJ, Kim SJ, Pesesky MW, Foston M, Dantas G, Moon TS. Comparative transcriptomics elucidates adaptive phenol tolerance and utilization in lipid-accumulating Rhodococcus opacus PD630. Nucleic Acids Res. 2016:44:2240-54.

10. Dal S, Trautwein G, Gerischer U. Transcriptional organization of genes for protocatechuate and quinate degradation from Acinetobacter sp. strain ADP1. Appl Environ Microbiol. 2005;71:1025-34.

11. Fischer R, Bleichrodt FS, Gerischer UC. Aromatic degradative pathways in Acinetobacter baylyi underlie carbon catabolite repression. Microbiology. 2008;154:3095-103.

12. Basu A, Apte SK, Phale PS. Preferential utilization of aromatic compounds over glucose by Pseudomonas putida CSV86. Appl Environ Microbiol. 2006:72:2226-30

13. Jimenez Jl, Minambres B, Garcia JL, Diaz E. Genomic analysis of the aromatic catabolic pathways from Pseudomonas putida KT2440. Environ Microbiol. 2002;4:824-41.

14. Kumar A, Kumar S, Kumar S. Biodegradation kinetics of phenol and catechol using Pseudomonas putida MTCC 1194. Biochem Eng J. 2005;22:151-9.
15. Ravi K, Garcia-Hidalgo J, Gorwa-Grauslund MF, Liden G. Conversion of lignin model compounds by Pseudomonas putida KT2440 and isolates from compost. Appl Microbiol Biotechnol. 2017;101:5059-70.

16. Sinigaglia M, Di Benedetto NA, Bevilacqua A, Corbo MR, Capece A, Romano P. Yeasts isolated from olive mill wastewaters from southern Italy: technological characterization and potential use for phenol removal. Appl Microbiol Biotechnol. 2010;87:2345-54.

17. Ahuatzi-Chacon D, Ordorica-Morales G, Ruiz-Ordaz N, Cristiani-Urbina E, Juarez-Ramirez C, Galindez-Mayer J. Kinetic study of phenol hydroxylase and catechol 1,2-dioxygenase biosynthesis by Candida tropicalis cells grown on different phenolic substrates. World J Microbiol Biotechnol. 2004:20:695-702

18. Alexieva Z, Gerginova M, Zlateva P, Manasiev J, Ivanova D, Dimova N. Monitoring of aromatic pollutants biodegradation. Biochem Eng J. 2008;40:233-40.

19. Harwood CS, Parales RE. The beta-ketoadipate pathway and the biology of self-identity. Annu Rev Microbiol. 1996;50:553-90.

20. Bugg TD, Ahmad M, Hardiman EM, Rahmanpour R. Pathways for degradation of lignin in bacteria and fungi. Nat Prod Rep. 2011;28:1883-96.

21. Pieper $\mathrm{DH}$. Aerobic degradation of polychlorinated biphenyls. Appl Microbiol Biotechnol. 2005;67:170-91.

22. Schlomann M. Evolution of chlorocatechol catabolic pathways. Conclusions to be drawn from comparisons of lactone hydrolases. Biodegradation. 1994;5:301-21.

23. Zaki S. Detection of meta- and ortho-cleavage dioxygenases in bacterial phenol-degraders. J Appl Sci Environ Manag. 2006;10:75-81.

24. Nicaud JM. Yarrowia lipolytica. Yeast. 2012;29:409-18.

25. Rodriguez GM, Hussain MS, Gambill L, Gao D, Yaguchi A, Blenner M. Engineering xylose utilization in Yarrowia lipolytica by understanding its cryptic xylose pathway. Biotechnol Biofuels. 2016;9:149.

26. Qiao K, Abidi SHI, Liu HJ, Zhang HR, Chakraborty S, Watson N, Ajikumar PK, Stephanopoulos G. Engineering lipid overproduction in the oleaginous yeast Yarrowia lipolytica. Metab Eng. 2015;29:56-65.

27. Blazeck J, Hill A, Liu LQ, Knight R, Miller J, Pan A, Otoupal P, Alper HS Harnessing Yarrowia lipolytica lipogenesis to create a platform for lipid and biofuel production. Nat Commun. 2014;5:3131.

28. Wang W, Wei H, Knoshaug E, Van Wychen S, Xu Q, Himmel ME, Zhang M. Fatty alcohol production in Lipomyces starkeyi and Yarrowia lipolytica. Biotechnol Biofuels. 2016;9:227.

29. Zhang S, Ito M, Skerker JM, Arkin AP, Rao CV. Metabolic engineering of the oleaginous yeast Rhodosporidium toruloides IFO0880 for lipid overproduction during high-density fermentation. Appl Microbiol Biotechnol. 2016;100:9393-405

30. Schwartz C, Shabbir-Hussain M, Frogue K, Blenner M, Wheeldon I. Standardized markerless gene integration for pathway engineering in Yarrowia lipolytica. ACS Synth Biol. 2017:6:402-9.

31. Schwartz CM, Hussain MS, Blenner M, Wheeldon I. Synthetic RNA polymerase III promoters facilitate high-efficiency CRISPR-Cas9mediated genome editing in Yarrowia lipolytica. Acs Synthetic Biology. 2016;5:356-9.

32. Shabbir Hussain M, Gambill L, Smith S, Blenner MA. Engineering promoter architecture in oleaginous yeast Yarrowia lipolytica. Acs Synth Biol. 2016:5:213-23.

33. Shabbir Hussain M, Rodriguez G, Gao D, Spagnuolo M, Gambill L, Blenner $M$. Recent advances in bioengineering of the oleaginous yeast Yarrowia lipolytica. AIMS Bioeng. 2016;3:493-514.

34. Blazeck J, Liu LQ Redden $H_{1}$ Alper $H$. Tuning gene expression in Yarrowia lipolytica by a hybrid promoter approach. Appl Environ Microbiol. 2011;77:7905-14.

35. Blazeck J, Reed B, Garg R, Gerstner R, Pan A, Agarwala V, Alper HS. Generalizing a hybrid synthetic promoter approach in Yarrowia lipolytica. App Microbiol Biotechnol. 2013:97:3037-52.

36. Dulermo R, Brunel F, Dulermo T, Ledesma-Amaro R, Vion J, Trassaert M, Thomas S, Nicaud JM, Leplat C. Using a vector pool containing variablestrength promoters to optimize protein production in Yarrowia lipolytica. Microb Cell Fact. 2017:16:31

37. Yaguchi A, Rives D, Blenner M. The new kids on the block: emerging oleaginous yeast of biotechnological importance. AIMS Microbiol. 2017:3:227-47

38. Görner C, Redai V, Bracharz F, Schrepfer P, Garbe D, Brück T. Genetic engineering and production of modified fatty acids by the non-conventional 
oleaginous yeast Trichosporon oleaginosus ATCC 20509. Green Chem. 2016:18:2037-46.

39. Evans CT, Ratledge C. A comparison of the oleaginous yeast, candida-curvata, grown on different carbon-sources in continuous and batch culture. Lipids. 1983;18:623-9.

40. Kourist R, Bracharz F, Lorenzen J, Kracht ON, Chovatia M, Daum C, Deshpande S, Lipzen A, Nolan M, Ohm RA, et al. Genomics and transcriptomics analyses of the oil-accumulating basidiomycete yeast Trichosporon oleaginosus: insights into substrate utilization and alternative evolutionary trajectories of fungal mating systems. MBio. 2015;6:e00918.

41. Abdelaziz OY, Brink DP, Prothmann J, Ravi K, Sun MZ, Garcia-Hidalgo J, Sandahl M, Hulteberg CP, Turner C, Liden G, Gorwa-Grauslund MF. Biological valorization of low molecular weight lignin. Biotechnol Adv. 2016;34:1318-46

42. Gong ZW, Shen HW, Zhou WT, Wang YD, Yang XB, Zhao ZKB. Efficient conversion of acetate into lipids by the oleaginous yeast Cryptococcus curvatus. Biotechnol Biofuels. 2015;8:189.

43. Meesters PAEP, Huijberts GNM, Eggink G. High cell density cultivation of the lipid accumulating yeast Cryptococcus curvatus using glycerol as a carbon source. Appl Microbiol Biotechnol. 1996;45:575-9.

44. Park WS, Murphy PA, Glatz BA. Lipid-metabolism and cell composition of the oleaginous yeast apiotrichum-curvatum grown at different carbon to nitrogen ratios. Can J Microbiol. 1990;36:318-26.

45. Anderson JJ, Dagley S. Catabolism of aromatic-acids in trichosporoncutaneum. J Bacteriol. 1980;141:534-43.

46. Gaal A, Neujahr HY. Metabolism of phenol and resorcinol in Trichosporon cutaneum. J Bacteriol. 1979;137:13-21.

47. Gonzalez-Garcia Y, Hernandez R, Zhang GC, Escalante FME, Holmes W, French WT. Lipids accumulation in Rhodotorula glutinis and Cryptococcus curvatus growing on distillery wastewater as culture medium. Environ Progress Sustain Energy. 2013;32:69-74.
48. Spanning A, Neujahr HY. The effect of glucose on enzyme-activities and phenol utilization in Trichosporon cutaneum grown in continuous culture. J Gen Microbiol. 1990;136:1491-5.

49. Georgopoulos SG, Zafiratos C, Georgiadis E. Membrane functions and tolerance to aromatic hydrocarbon fungitoxicants in conidia of Fusarium Solani. Physiologia Plant. 1967;20:373.

50. Huertas MJ, Duque E, Molina L, Rossello-Mora R, Mosqueda G, Godoy P, Christensen B, Molin S, Ramos JL. Tolerance to sudden organic solvent shocks by soil bacteria anal characterization of Pseudomonas putida strains isolated from toluene polluted sites. Environ Sci Technol. 2000;34:3395-400.

51. Tsitko IV, Zaitsev GM, Lobanok AG, Salkinoja-Salonen MS. Effect of aromatic compounds on cellular fatty acid composition of Rhodococcus opacus. Appl Environ Microbiol. 1999;65:853-5.

52. Sikkema J, Debont JAM, Poolman B. Interactions of cyclic hydrocarbons with biological membranes. J Biol Chem. 1994;269:8022-8.

53. Udaondo Z, Molina L, Daniels C, Gomez MJ, Molina-Henares MA, Matilla MA, Roca A, Fernandez M, Duque E, Segura A, Ramos JL. Metabolic potential of the organic-solvent tolerant Pseudomonas putida DOT-T1E deduced from its annotated genome. Microb Biotechnol. 2013;6:598-611.

54. Ramos-Gonzalez MI, Godoy P, Alaminos M, Ben-Bassat A, Ramos JL. Physiological characterization of Pseudomonas putida DOT-T1E tolerance to p-hydroxybenzoate. Appl Environ Microbiol. 2001;67:4338-41.

55. Beney L, Gervais P. Influence of the fluidity of the membrane on the response of microorganisms to environmental stresses. Appl Microbiol Biotechnol. 2001;57:34-42.

56. Adeboye PT, Bettiga M, Olsson L. ALD5, PAD1, ATF1 and ATF2 facilitate the catabolism of coniferyl aldehyde, ferulic acid and p-coumaric acid in Saccharomyces cerevisiae. Sci Rep. 2017;7:42635.

\section{Submit your next manuscript to BioMed Central and we will help you at every step:}

- We accept pre-submission inquiries

- Our selector tool helps you to find the most relevant journal

- We provide round the clock customer support

- Convenient online submission

- Thorough peer review

- Inclusion in PubMed and all major indexing services

- Maximum visibility for your research

Submit your manuscript at www.biomedcentral.com/submit
O Biomed Central 